\title{
Deshibición, espontaneidad y codificación percibida por el alumnado de expresión corporal
}

\author{
Inma Canales-Lacruz* \\ María Inés Táboas-Pais** \\ Ana Rey-Cao ${ }^{* * *}$
}

\begin{abstract}
Resumo: Este artículo examina las percepciones del alumnado en cuanto a la desinhibición, la espontaneidad y la codificación de las tareas en la disciplina de expresión corporal. La muestra fue de 18 personas - 24,46 $\pm 2,22$ años-; alumnos/as de la Universidad de Vigo (España). Se realizó análisis de contenido de los diarios de prácticas del alumnado. El tratamiento de la información se realizó con el software de análisis cualitativo NVIVO 8. Los resultados mostraron que: la interacción visual y táctil inhibe el compromiso expresivo, las consignas basadas en metáforas facilitan el movimiento espontáneo y la codificación del gesto favorece la transmisión de mensajes

Palabras clave: Educación. Percepción. Danza.
\end{abstract}

\section{INTRODUCCIÓN}

La expresión corporal como contenido curricular de la educación física se caracteriza por la elevada implicación emocional del alumnado (HANNA, 2008). Esta implicación viene determinada porque las tareas expresivas se fundamentan en la estimulación de la singularidad y de la creatividad motriz (CANALES, 2011; STOKOE; SIRKIN, 1994). A través de la exploración de las posibilidades motrices se favorece el descubrimiento de la individualidad motriz que prescinde de la estandarización y de la eficacia motriz (ARTEAGA; VICIANA; CONDE, 1999).

\footnotetext{
'Doctora. Departamento de expresión plástica, musical y corporal. Facultad de Educación . Universidad de Zaragoza. Zaragoza. España. E-mail: bromato@unizar.es

"Doctora. Departamento de ciencias de la actividad física y del deporte. Universidad Católica de San Antonio de Murcia. Murcia. España.E-mail: mtaboas@ucam.edu

"'Doctora. Departamento de didácticas especiales. Facultad de ciencias de la educación y del deporte. Universidad de Vigo. Vigo. España. E-mail: anacao@uvigo.es
} 
Precisamente, esta inexistencia de un modelo motriz, tan usual en las propuestas de educación física, junto con la novedad que supone el contenido de expresión corporal, provoca nerviosismo e inseguridad en el compromiso motriz del alumnado (SIERRA, 2002). Incluso las propuestas introyectivas que inducen hacia el autoconocimiento son percibidas como espacios de inseguridad y provocan timidez en el alumnado (ROVIRA, 2010).

Prisbell (1988) demostró que los individuos con altos niveles de timidez sentían que los demás les percibían negativamente, mientras que los individuos con bajos niveles de timidez mostraban lo contrario. En consecuencia, la desinhibición debe ser uno de los objetivos que modulen las propuestas de expresión corporal, para así, proporcionar espacios de seguridad que posibiliten los procesos exploratorios (MEIRIEU, 1988).

\subsection{LA RELEVANCIA DE LA MIRADA Y EL TACTO EN LA DESINHIBICIÓN}

La influencia que ejerce la presencia del receptor/a en el emisor/ a del mensaje es muy evidente (BILBENY, 1997; MERLEAUPONTY, 1980). Acciones tan cotidianas como la de observar y ser observado/a; tocar y ser tocado/a, desencadenan restricciones y bloqueos, aminorando la exploración de la singularidad y creatividad motriz (CANALES, 2011).

La mirada se deposita en los demás, pero al mismo tiempo, se hace aparente ante la mirada de los demás, el "cuerpo es a la vez vidente y visible" (MERLEAU-PONTY, 1980, p.17). Esta exposición está dotada de un juicio social, de una valoración, en la que el observado/a considera que está siendo procesado por la opinión del observador/a (BOURDIEU, 1986). La simultaneidad de la interacción visual es uno de los aspectos trascendentales que dotan de gran sentido comunicativo a la mirada.

Por su parte, la interacción táctil es imprescindible para un adecuado desarrollo del individuo. Esta interacción se vincula con el ámbito familiar, de lo íntimo y privado; construyéndose una actitud refinada hacia el tacto, discriminando las zonas corporales que pueden ser tocadas y las que quedan excluidas (BILBENY, 1997). 
Además, otro aspecto que vincula el tacto con el ámbito privado es la conexión que tiene con la sexualidad, y cómo ésta, se confunde con la genitalidad (BILBENY, 1997). Gill Westland (2011) diseñó un estudio partiendo del hecho constatable que el tacto provoca ansiedad y se relaciona con la provocación sexual y/o la agresión física.

Por todo ello, la interacción táctil y visual son dos criterios clave que deben articular las propuestas de los programas de expresión corporal, ya que ambas interacciones inhiben las respuestas expresivas del alumnado (CANALES, 2011).

\subsection{LAS EMOCIONES DEL ALUMNADO ANTE LAS PROPUESTAS DE EXPRESIÓN CORPORAL}

La revisión de la bibliografía sobre la expresión corporal y la danza revela el enfoque multidisciplinar con el que son abordadas. Sevdalis y Keller (2011) en un artículo de revisión sobre estudios empíricos de danza manifiestan la necesidad de estimular la investigación futura sobre los aspectos socio-cognitivos de la danza, requiriendo de una perspectiva integradora que identifique las conexiones entre los diferentes niveles de análisis.

Esta interdisciplinariedad es indispensable porque la expresión corporal y la danza son disciplinas que promueven la solución creativa a los problemas propuestos, y en la que se comunican emociones e ideas a través de procedimientos multidimensionales vertebrados por la imaginación. Parafraseando a Hanna (2008), a través de las tareas expresivas los alumnos/as experimentan el afecto cognitivo y su trascendencia en el cuerpo.

La tipología de las tareas determinan las emociones de los participantes. Esta relación fue analizada por De Sousa y Caramshi (2011) cuando plantearon un proceso de aprendizaje de bailes de salón con adolescentes. Cuando la enseñanza de los pasos de bailes se efectuó por separado los alumnos/as mostraban satisfacción y bienestar. Por el contrario, cuando el docente solicitó constituir libremente parejas, el $60 \%$ esquivaron y dilataron el proceso incluyendo otro tipo de acciones como hablar con los demás, 
ausentarse para ir al baño, etc. Estas emociones de vergüenza experimentadas estaban suscitadas por el miedo a invadir el espacio del compañero/a y por la novedad de las actividades.

La investigación de Torrents et al. (2011) analizó las respuestas emocionales del alumnado y su influencia según el tipo de tarea de expresión corporal. Los resultados mostraron que el alumnado sentía emociones positivas ante las tareas expresivas. Cuando se trataba de emociones negativas, era la vergüenza la que aparecía de forma mayoritaria.

\subsection{LA ESPONTANEIDAD EN LAS PROPUESTAS DE EXPRESIÓN CORPORAL}

El vínculo entre emotividad y creatividad también incluye a los procesos de improvisación. La improvisación es un recurso comúnmente utilizado para desarrollar la creatividad, y ha sido motivo de estudio en una investigación aplicada a bailarines de danza contemporánea para constatar cómo se entendían cuando improvisaban (RIBEIRO; FONSECA, 2011). La clave de esta comunicación radicó en la empatía, la capacidad que tiene el ser humano para comprender las emociones del otro.

La espontaneidad en la expresión corporal está vinculada a la respuesta instantánea del alumnado ante los estímulos propuestos en las tareas expresivas. Se pretende que el alumnado prescinda de tiempo de reflexión para expresarse de forma instintiva y así emitir respuestas precarias. El movimiento espontáneo está mínimamente manipulado por el proceso racional para que fluya de acuerdo al estado emocional experimentado en el momento de expresión (SANTIAGO, 1985).

Algunos de los estímulos utilizados en las tareas expresivas para desencadenar movimientos espontáneos son las consignas basadas en la metáfora. Las metáforas surgen de procesos de pensamiento y conceptualización, y la sinestesia puede ser una clase de metáfora perceptiva en las que las cualidades de una clase o modalidad de experiencia perceptual se transfieren a otra, como por ejemplo cuando los colores se atribuyen a sabores, olores a notas musicales (MARKS, 1978). 
De hecho, las sinestesias se han convertido en uno de los recursos más utilizados en la formación de metáforas (FAJARDO, 2006). Su capacidad de evocación sensorial e imaginativa ayuda al alumnado a llegar al tipo de acciones motrices que se pretende, orientando la exploración pero sin limitar las posibilidades de respuesta (TORRENTS, 2012). Un estudio realizado con niños pequeños comparó los resultados en las habilidades de baile ante instrucciones metafóricas verbales y otro tipo de instrucciones. Los datos establecían mejores resultados en la ejecución cuando se utilizaban instrucciones verbales metafóricas a otro tipo de instrucciones (SAWADA; MORI; ISHII, 2002).

\subsection{LA CODIFICACIÓN DEL GESTO}

La codificación del gesto facilita la organización de la espontaneidad del gesto expresivo para convertirlo en un gesto comunicativo comprensible para el receptor/a (COCA, 1988). Se trata de transformar el movimiento espontáneo, que se caracteriza por su anarquía y precariedad, en un movimiento codificado que posea una intención comunicativa.

Lagerlof y Dierf (2009) estudiaron la codificación del movimiento con el reconocimiento de los mensajes percibidos por parte de la persona receptora. Demostraron que la fuerza y el ritmo del movimiento eran claves para poder reconocer las emociones representadas. En esta misma línea de la codificación del gesto, Lussier-Ley y Durand-Bush (2009) verificaron el íntimo vínculo que tenían los sentimientos con las experiencias creativas en el proceso de creación y las emociones de bailarines profesionales.

\subsection{Propuesta del PRESEnte Estudio}

Este trabajo pretende conocer las percepciones del alumnado de expresión corporal en cuanto a la desinhibición, la espontaneidad y la codificación, aspectos que organizan las tareas expresivas propuestas por un programa de intervención de expresión corporal (CANALES, 2010a, 2010b). 
Las hipótesis planteadas son: 1. La interacción visual y táctil inhiben el compromiso expresivo de los alumnos/as en las tareas expresivas. 2. Las consignas basadas en las metáforas facilitan el movimiento espontáneo. 3. La codificación del gesto favorece la transmisión de mensajes con intención comunicativa.

\section{MÉTodo}

\subsection{Participantes}

La población objeto de estudio de la investigación está constituida por 18 personas que participaron como alumnado en la asignatura de expresión corporal de la licenciatura en ciencias de la actividad física y del deporte. Esta asignatura se impartió en la Facultad de Ciencias de la Educación y del Deporte de la Universidad de Vigo (España).

La muestra seleccionada es intencionada de carácter noaleatorio y está formada por 18 sujetos -11 hombres y 7 mujerescon una media de edad de $24,46 \pm 2,22$.

Los criterios de selección de la muestra fueron: grado de participación y expresión escrita. El grado de participación se refiere a la asistencia a las sesiones prácticas de la asignatura de expresión corporal. Sólo las personas que siguieron la actividad de forma continuada -asistencia a más del $80 \%$ de las 12 sesiones- podían tener una visión integral de la asignatura. La expresión escrita se refiere a una adecuada expresión narrativa que posibilitase la profundidad en las descripciones de las experiencias y permitiese conocer la percepción sobre las tareas expresivas.

\subsection{VARIABLES}

La variable independiente es una propuesta de intervención didáctica de expresión corporal (CANALES, 2010a; 2010b), que concibe la expresión corporal como vehículo de desarrollo de la 
desinhibición, la creatividad y la singularidad motriz. La propuesta se estructura en tres fases de actuación (CANALES, 2011): exploración, expresión y comunicación.

Entre sus objetivos se encuentran la exploración de las posibilidades motrices y la desinhibición en las tareas expresivas primera fase de aplicación, exploración-, la estimulación de la singularidad motriz a partir del movimiento espontáneo -segunda fase, expresión-, y la utilización de la codificación gestual para transmitir un mensaje -tercera fase, comunicación-.

Se impartieron 12 sesiones prácticas de una hora de duración, aplicadas en dos sesiones semanales distribuidas en las tres fases de aplicación. El esquema de las sesiones se expone en el siguiente cuadro.

Cuadro 1- Distribución de las sesiones

\begin{tabular}{cll}
\hline & Sesión 1 & Tareas con ausencia visual \\
& Sesión 2 & Tareas con ausencia visual y de tacto con objetos \\
& Sesión 3 & Tareas con ausencia visual y de tacto interpersonal \\
Fase exploración & Sesión 4 & Tareas con ausencia visual del observado/a \\
& Sesión 5 & Tareas con presencia visual \\
& Sesión 6 & Tareas con presencia visual y de tacto interpersonal \\
\hline \multirow{2}{*}{ Fase expresión } & Sesión 7 & Tareas de estímulos objetuales \\
& Sesión 8 & Tareas de estímulos cromáticos \\
\hline \multirow{2}{*}{ Fase comunicación } & Sesión 9 & Tareas de codificación del rostro \\
& Sesión 10 & Tareas de codificación del tronco y miembros superiores \\
& Sesión 11 & Tareas de codificación de miembros inferior es \\
& Sesión 12 & Match de la improvisación \\
\hline
\end{tabular}

Fuente: Elaboración propia

Las variables dependientes son la interacción visual, la interacción táctil, el movimiento espontáneo y la codificación del gesto.

\subsection{INSTRUMENTOS}

La recogida de las percepciones del alumnado se realizó a través de un diario de prácticas que fue cumplimentado por los propios participantes. En el diario reflejaron sus experiencias sobre las tareas expresivas realizadas en las sesiones prácticas. 
Para analizar las percepciones registradas se utilizó el análisis de contenido. En la tabla 2 se presenta el sistema de categorías construido para poder efectuar el análisis. Dicho sistema es una adaptación de Canales (2011).

Este sistema de categorías identifica las fases de aplicación de la propuesta de intervención -exploración, expresión y comunicaciónposibilitando el procesamiento de la información. Para su elaboración se siguió un proceso inductivo y deductivo, ya que se parte de un modelo teórico sobre el objeto de estudio que es modelado ad hoc adaptándose a los testimonios de los informantes y a la coherencia de la intervención.

Cuadro 2 - Sistema de categorías

\begin{tabular}{lll}
\hline \multicolumn{1}{c}{ Dimensiones } & \multicolumn{1}{c}{ Categorías } & \multicolumn{1}{c}{ Indicadores } \\
\hline & 1.1. Interacción visual & 1.1.1. Observado/a \\
1. Fase exploración & & 1.1.2. Observador/a \\
& 1.2. Interacción táctil & 1.2.1. Emisor/a \\
2. Fase expresión & 2.1. Movimiento espontáneo & 2.1.1. Estúmulo \\
3. Fase comunicación & 3.1. Codificación gestual & 3.1.1. Esquema corporal \\
\hline
\end{tabular}

Fuente: Elaboración propia

El sistema de categorías elaborado cumple los requisitos planteados por Heineman (2003). En primer lugar, se adecua al objeto de estudio, es decir, refleja las intenciones de la búsqueda. En segundo lugar, sus categorías e indicadores satisfacen los criterios de exhaustividad y de mutua exclusividad. Finalmente, la objetividad y fidelidad del sistema permite que los fragmentos de un mismo material puedan ser codificados de la misma manera por distintos analistas.

Para el análisis de contenido de los diarios se utilizó el programa informático QSR-NVIVO 8 diseñado para el análisis de datos en investigaciones basadas en métodos cualitativos. Esta herramienta permite indizar los fragmentos seleccionados según el sistema de categorías empleado y posibilita unos índices cuantitativos de cada uno de los indicadores, en cuanto al número de párrafos, su porcentaje con respecto a los otros indicadores, número de informantes que componen la compilación, etc. 


\subsection{Procedimiento}

La cumplimentación del diario de prácticas se realizó de cada una de las sesiones prácticas de la asignatura, esto es, un total de 12 sesiones prácticas distribuidas en el segundo semestre del curso. Cada sesión práctica finalizaba cinco minutos antes, para que así, el alumnado pudiese apuntar los principales aspectos experimentados a lo largo de la sesión. La redacción final se realizó fuera del aula, para que el alumnado reflejase extensamente las experiencias suscitadas.

El diario formó parte de la evaluación de la asignatura. Se valoró exclusivamente la profundidad de las descripciones, excluyendo la valoración de las tareas o de los procedimientos pedagógicos.

El proceso de elaboración del sistema de categorías utilizado como instrumento para el análisis de contenido se ejecutó en tres fases que se corresponden con los controles a los que debe ser sometido un instrumento para demostrar su validez, fiabilidad, objetividad y utilidad práctica (HEINEMANN, 2003):

1. Prueba piloto inicial. Consistió en un primer acercamiento al objeto de estudio con el fin de conocer las posibilidades de adaptación del sistema de categorías de Canales (2011).

2. Segunda prueba piloto. Se realizó un segundo análisis para elaborar el sistema definitivo expuesto anteriormente en el Cuadro 2 .

3. Triangulación con observadoras. Se efectuó una triangulación con tres investigadoras, aplicando el sistema de categorías en diferentes fragmentos de diarios. Se realizó una sesión previa de entrenamiento de las observadoras.

\section{Resultados}

El total de palabras recogidas a través de los diarios del alumnado fue de 11.296. De ellas, fueron codificadas 4.813 palabras, lo que supuso un total de 162 referencias en relación a las categorías 
de análisis. De forma general, se puede apreciar que 92 de las 162 referencias encierran valoraciones positivas de las vivencias durante las clases de expresión corporal. Por el contrario, 67 referencias aluden a vivencias negativas durante estas sesiones. A continuación, se detalla cuáles han sido las situaciones que de forma generalizada han generado unas u otras vivencias entre el alumnado.

\subsection{FASE EXPLORACIÓN}

En este apartado se muestran los resultados obtenidos de las sesiones de la fase de la exploración. Las tareas de esta fase tienen el propósito de introducir al alumnado en el proceso de desinhibición ante las tareas expresivas. Para ello, se propone una secuencia progresiva de menor a mayor compromiso emocional, siendo la interacción visual y táctil los ejes vertebradores.

La interacción visual ha sido analizada según la perspectiva del observado/a y observador/a. Se debe recordar que las tareas de las primeras sesiones se realizaron en ausencia visual, para ir incorporando la presencia visual de forma progresiva a lo largo de las sesiones de esta fase.

Desde la perspectiva del observado/a destaca que el 48,8\% de los informantes muestran una valoración negativa de la presencia visual y un 36,6 \% afirman la valoración positiva de la ausencia visual (Gráfico 1).

Gráfico 1- Interacción visual: perspectiva del observado/a

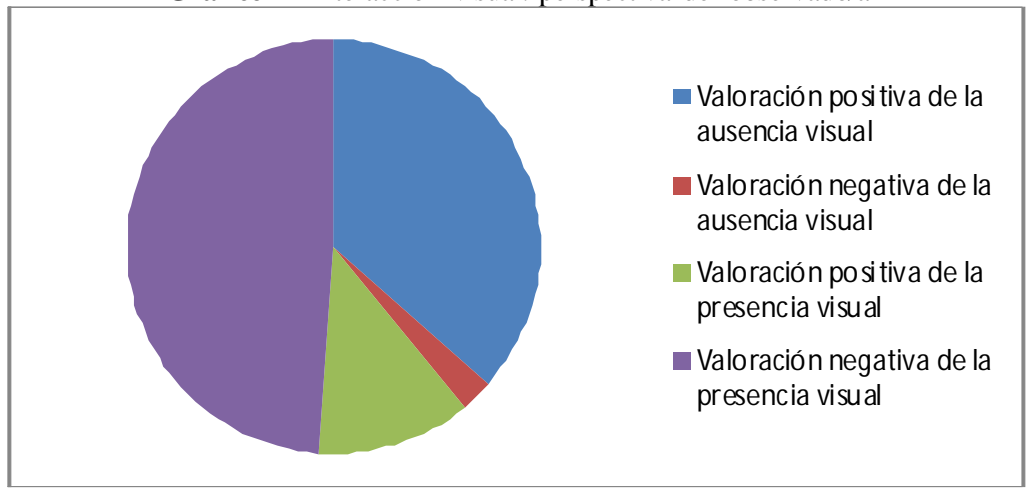

Fuente: Elaboración propia

Movimento, Porto Alegre, v. 19, n. 04, p. 119-140, out/dez de 2013. 
Los testimonios reflejan la vergüenza y timidez cuando son observados/as, restringiendo por ello su comportamiento expresivo. Sin embargo, cuando las tareas son en ausencia visual se favorece la desinhibición, facilitando la concentración y la toma de conciencia. Es decir, sentirse observado/a condiciona de forma negativa la implicación en las tareas expresivas, ya que, consideran que son motivo de la valoración del observador/a.

Desde la perspectiva del observador/a destaca el 50\% de personas que muestran una valoración negativa cuando observan a un compañero/a con capacidad visual, y un 21,4\% la valoración positiva de observar a un compañero/a en ausencia visual. Ambos resultados apuntan en la línea de lo positivo que es observar cuando no existe reciprocidad visual, es decir, cuando el observado/a permanece con los ojos cerrados. En contrapartida, el 28,6 \% valora de positivo el observar a los demás cuando permanecen con los ojos abiertos -gráfico 2 .

Gráfico 2 - Interacción visual: perspectiva del observador/a

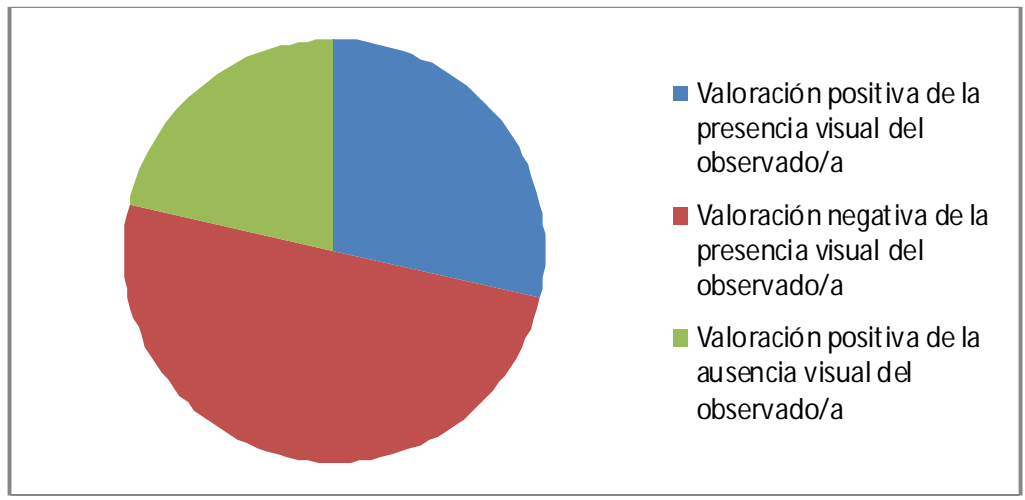

Fuente: Elaboración propia

Los observadores/as disfrutan de lo visionado cuando constatan satisfacción y comodidad en las acciones de los observados/as. Por su parte, cuando el comportamiento expresivo del observado/a se caracteriza por la restricción, el observador/a empatiza y manifiesta 
su incomodidad. También se admite la desconcentración que provoca el visionar las respuestas expresivas de los demás, generando inseguridad y dispersión en las propias acciones.

Observar sin reciprocidad visual genera libertad y tranquilidad en la acción, ya que desaparece la posibilidad de alternancia de rol de observador/a a observado/a.

La interacción táctil ha sido analizada según la perspectiva del emisor/a y receptor/a. Se debe recordar que las tareas de esta fase incorporaban de forma progresiva la interacción táctil.

El $62,5 \%$ de los emisores/as valoran de forma positiva la interacción táctil. El 37,5\% afirman lo contrario. El $70 \%$ de los receptores/as valoran de forma positiva el tacto. El $30 \%$ afirman lo contrario (Gráfico 3).

Gráfico 3- Interacción táctil: perspectiva del emisor/a y receptor/a

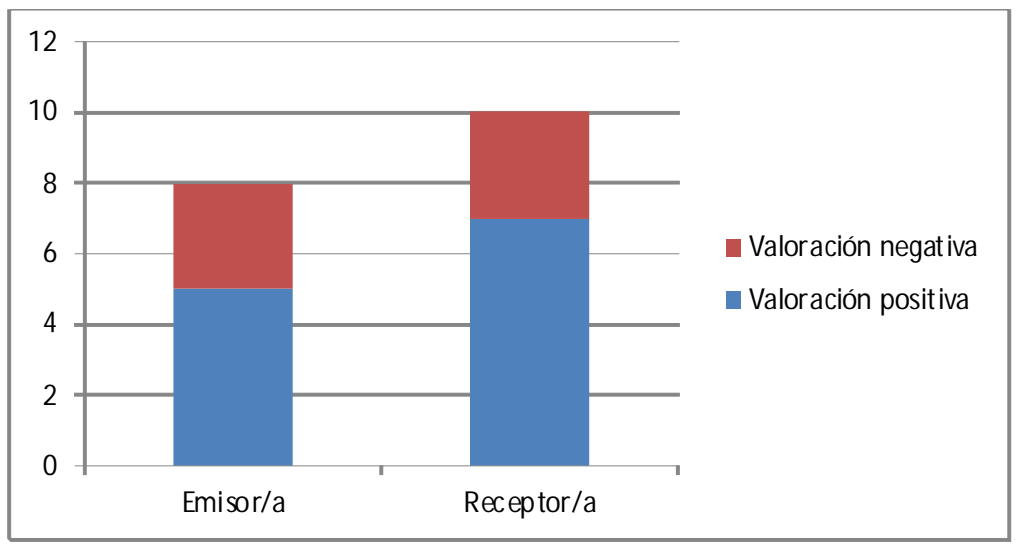

Fuente: Elaboración propia

Muchos de los testimonios aluden a la comodidad que produce el hecho de tocar a los demás a través de objetos. También valoran el aprendizaje adquirido en torno al esquema corporal a partir de algunas tareas de interacción táctil. El pudor por tocar determinadas zonas corporales y el temor a aplastar al receptor/a, son algunas de las valoraciones negativas de los emisores/as. 
La relajación y el propio conocimiento corporal, son algunos de los aspectos que destacan de forma positiva los receptores/as. Sin embargo, recibir el tacto interpersonal por parte de algún compañero/ a con el que no se tiene excesiva confianza, produce cierto malestar.

\subsection{LA EXPRESIÓN}

En este apartado se muestran los resultados obtenidos de las sesiones de la fase de la expresión. Los diferentes estímulos propuestos a partir de las tareas, actúan como catalizadores del movimiento espontáneo, propósito de esta fase de aplicación.

El 69\% valoran de forma positiva la utilización de metáforas corporales como estímulo de la espontaneidad. El $31 \%$ se muestran contrarios -gráfico 4-.

Gráfico 4- El movimiento espontáneo: la metáfora

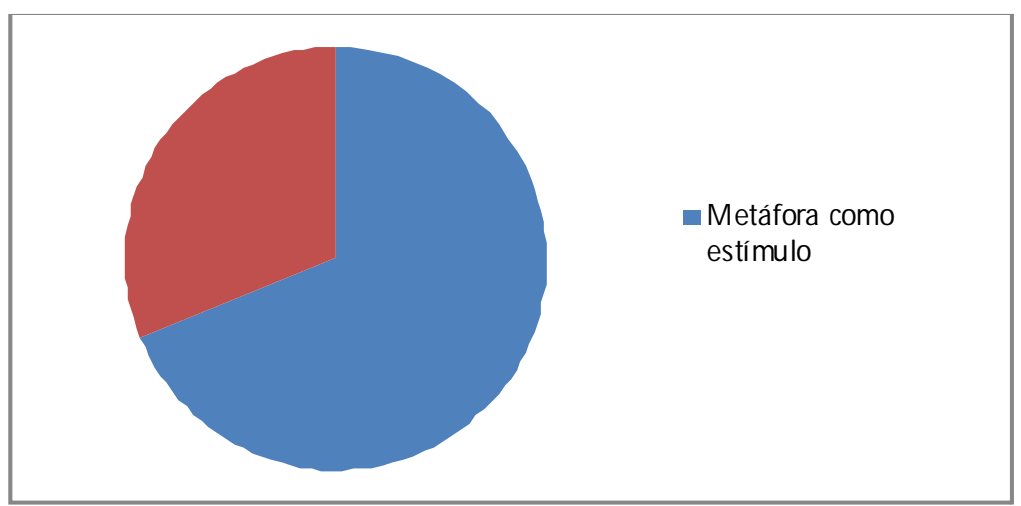

Fuente: Elaboración propia

La originalidad de los estímulos recibe las mejores valoraciones del alumnado. Las metáforas propuestas motivan la participación, así como, la libertad de acción que posibilitan.

Aunque minoritarias, también hay testimonios que muestran las dificultades que entraña la utilización de metáforas corporales. La capacidad de abstracción artística que requieren las metáforas corporales es la que provoca mayor conflicto. 


\section{ArtigosOriginais}

\subsection{FASE COMUNICACIÓN}

En este apartado se muestran los resultados obtenidos de las sesiones de la fase de la comunicación. Las tareas de estas sesiones pretenden proporcionar al alumnado de recursos para codificar el gesto, y así, poder transmitir un mensaje con intención comunicativa.

El $42,8 \%$ valoran de forma positiva el descubrimiento que ha supuesto la codificación del gesto, indicando su potencialidad a la hora de precisar el mensaje a comunicar. El 14,3\% resalta la diversión que produce el proceso de codificación, mientras que el 42,8\% detalla la dificultad que entraña dicho proceso.

Gráfico 5- La codificación del gesto

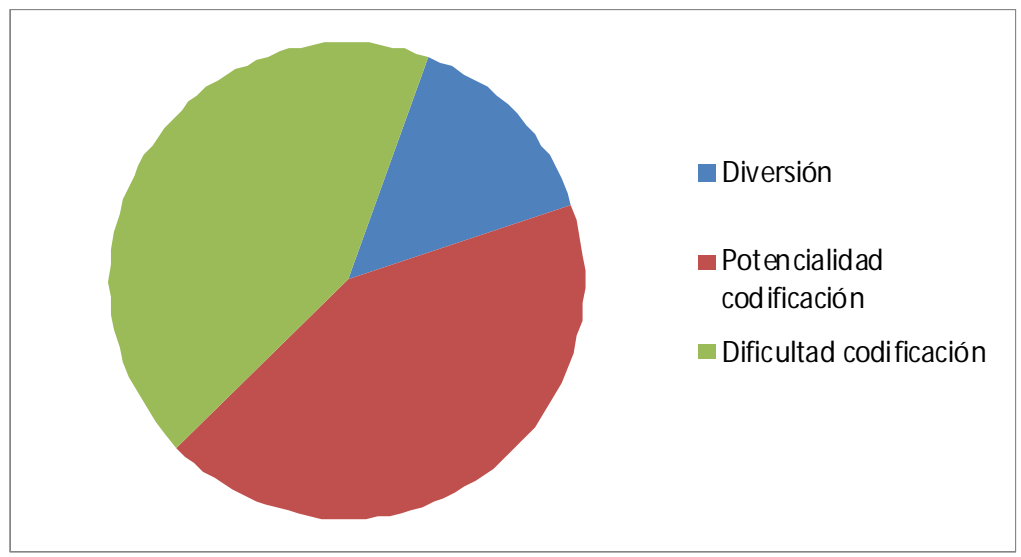

Fuente: Elaboración propia

La mayoría de las referencias positivas aluden a la satisfacción que produce las creaciones grupales en las que deben organizar el gesto para construir un mensaje. Aplicar la codificación corporal con intención comunicativa produce resultados sorprendentes, los cuales, son valorados muy positivamente por los informantes. También añaden el agrado que produce descubrir la potencialidad del gesto para transmitir información. 
Aunque de forma minoritaria, algunos testimonios resaltan las dificultades que entraña la disociación corporal cuando se trata de combinar las codificaciones de los diferentes segmentos corporales.

\section{Discusión}

Los testimonios escritos del alumnado que participó en esta investigación desvelan el alto grado de implicación emocional que desencadenan las tareas expresivas. Así lo ponen de relevancia las 4.813 palabras que los alumnos/as dedican a describir sus emociones de las 11.296 que constituyeron los diarios. Se constata la idea de Hanna (2008) en cuanto que la expresión corporal se distingue por un alto grado de implicación emocional.

Con respecto a la primera hipótesis planteada "la interacción visual y táctil inhiben el compromiso expresivo de los alumnos/as en las tareas expresivas", se constatan las teorías de la comunicación que manifiestan la influencia que ejerce el receptor/a en el emisor/a del mensaje (BILBENY, 1997; MERLEAU-PONTY, 1980). Los resultados extraídos de la primera fase de la exploración son coincidentes con la investigación de Canales (2011). La interacción visual y táctil ejerce una influencia en el comportamiento del receptor/ a y del emisor/a, sobre todo en forma de restricción motriz.

Esta investigación no puede confirmar los resultados de Torrents et al. (2011) en cuanto que las valoraciones negativas son mínimas con respecto a las positivas. Aunque los resultados generales de la presente investigación muestran un número mayor de referencias positivas que negativas -92 positivas y 67 negativas-, no se puede admitir que la presencia de las negativas sea mínima.

Por su parte, sí se puede ratificar la presencia de la vergüenza como una de las emociones negativas más acusadas. La exposición que entrañan las tareas expresivas es experimentada mayoritariamente con valoraciones negativas, tales como timidez y verguienza. Estos resultados confirman que el observado/a considera que es susceptible de ser juzgado por el observador/a (BOURDIEU, 1980). 
Los resultados de Prisbell (1988) en cuanto que los individuos con altos niveles de timidez sentían que los demás les percibían negativamente, no han podido ser corroborados por la presente investigación, ya que, no se aplicaron instrumentos para analizar la timidez del alumnado, por lo que no se pudo vincular las expectativas de juicio social con el grado de timidez del individuo.

La percepción del alumnado en las tareas con presencia visual evidencia como el hecho de la simultaneidad del observador/aobservado/a, inherente en la interacción visual (MERLEAUPONTY, 1980), genera inseguridad y turbación porque el observador/ a es susceptible de convertirse en cualquier momento en observado/ a. Se confirma el resultado de Torrents et al. (2011) en cuanto que las tareas con ojos abiertos tienen una correlación negativa con la felicidad.

La insatisfacción referenciada por los observadores/as está desencadenada por los bloqueos percibidos en sus compañeros/as. Es decir, es la empatía la que permite reconocer las emociones de los demás y compartir sus estados afectivos. De la misma manera, el observador/a disfruta de lo visionado cuando el compañero/a transmite felicidad y libertad en su implicación motriz. Este resultado confirma la presencia de la empatía en las propuestas de expresión corporal, como también lo ratifican Ribeiro y Fonseca (2011).

Otra de las valoraciones procedentes de los observadores/as es la dispersión que les produce comprobar las respuestas expresivas de los demás. La carencia de un estereotipo motriz que dirija sus acciones y la falta de experiencia en el ámbito de la expresión corporal, establecen una actitud de nerviosismo e inseguridad. Estos resultados reafirman los mostrados por la investigación de Miguel Ángel Sierra (2002) y de Glòria Rovira (2010). La novedad de las prácticas propuestas fue también una de las causas de la turbación mostrada por los adolescentes analizados por De Sousa y Camaschi (2011) en el aprendizaje de bailes de salón.

Las percepciones del alumnado de la presente investigación en cuanto a la interacción táctil son mayoritariamente positivas. Estos 
resultados confirman las teorías sobre el desarrollo humano que vinculan una adecuada evolución de las capacidades humanas con el tacto, y cómo este vínculo, convierte al individuo en acólito de dicha comunicación (BILBENY, 1997).

Los emisores/as destacan que el recurso de los objetos -pelotas, pañuelos, cuerdas, etc.- actúa como mitigador de la vergüenza y del reparo. Los receptores/as señalan la relajación, así como, el propio conocimiento corporal, como los principales aspectos positivos que entrañan las tareas con interacción táctil interpersonal. Estas emociones positivas ratifican los resultados de Torrents et al. (2011) en cuanto que las tareas en pareja se correlacionan positivamente con el sentimiento del amor. También ese autoconocimiento corporal desencadenado por la interacción táctil del emisor/as es coincidente con los resultados de Rovira (2010).

Por su parte, es el pudor por tocar determinadas zonas corporales y el temor a dañar al compañero/a, las principales causas que generaron malestar a los emisores/as del tacto. El pudor por tocar determinadas zonas corporales está determinado por la confusión de sexualidad con genitalidad (BILBENY, 1997). Se confirman los resultados de Westland (2011) en cuanto que el tacto provoca ansiedad porque se relaciona con la provocación sexual y con la agresión física. El temor a dañar al compañero/a se encuentra también en los resultados de De Sousa y Caramshi (2011), en cuanto que la invasión del espacio del compañero/a en bailes de salón provoca vergüenza, sobre todo derivados por el temor a pisarle.

Cuando el alumnado participante en la presente investigación mostró emociones reticentes a recibir el tacto, estaba relacionado con la falta de confianza con el emisor/a, confianza relacionada con el grado de amistad. Estos resultados no concuerdan con los hallados por De Sousa y Caramshi (2011), ya que, la vergüenza suscitada por los bailes de salón estaba desvinculada del grado de amistad entre el alumnado porque la mayoría de los integrantes del grupo llevaban varios años juntos en el colegio. La diferencia cronológica de la muestra de las dos investigaciones puede ser el motivo por el que los 
datos difieren. La investigación de los bailes de salón (DE SOUSA; CARAMSHI, 2011) fue aplicada a adolescentes, mientras que la presente utilizó al alumnado universitario, en la que todos los individuos superan los 20 años. Es la adolescencia el periodo de máxima exploración sexual, y de ahí que, actividades que requieran proximidad corporal provoquen nerviosismo y pudor, a pesar del grado de amistad que vincule a los individuos.

Con respecto a la segunda hipótesis planteada en la presente investigación, "las consignas basadas en la metáforas facilitan el movimiento espontáneo", los testimonios procedentes de las tareas de la segunda fase de la expresión valoraron de forma positiva los estímulos propuestos en las tareas. Concretamente mencionan la utilidad de las metáforas como catalizadores del movimiento espontáneo. Los factores destacados son la originalidad de los estímulos y la libertad de acción que promueven. Es decir, se puede admitir que el movimiento espontáneo está mínimamente regulado racionalmente, lo que le dota de mayor fluidez expresiva (SANTIAGO, 1985).

De todos los estímulos utilizados en las tareas de la fase de expresión, es la metáfora verbal la que han destacado mayoritariamente. De esta manera, se corroboran los resultados de Sawada, Mori e Ishii (2002) en cuanto que las metáforas verbales son instrucciones adecuadas para estimular las habilidades expresivas.

La tercera hipótesis planteada, "la codificación del gesto favorece la transmisión de mensajes con intención comunicativa", se manifiesta en el tipo de emotividad implícita en las referencias de las tareas de la tercera y última fase de la comunicación. El proceso de creación está íntimamente vinculado con los sentimientos experimentados (LUSSIER-LEY; DURAND-BUSH, 2009) y la mayoría de las referencias positivas de las tareas de la fase de la comunicación aluden a la satisfacción que produce las creaciones grupales en las que deben organizar el gesto para construir un mensaje. Uno de los aspectos destacados son los resultados 
sorprendentes derivados de la codificación del gesto, que reportan al alumnado satisfacción por lo producido. La codificación del gesto permitió constituir mensajes comprensibles para los receptores/as (COCA, 1988; LAGERLOF; DIERF, 2009).

\section{CONCLUSIONES}

Para poder promover propuestas de expresión corporal que se fundamenten en la singularidad y la creatividad motriz (CANALES, 2011; STOKOE; SIRKIN, 1994), es necesario constituir escenarios de seguridad (MEIRIEU, 1988), en los que el alumnado pueda explorar sus posibilidades motrices, promoviendo el descubrimiento de la idiosincrasia motriz (ARTEAGA; VICIANA; CONDE, 1999).

Analizar las emociones suscitadas por las experiencias vinculadas a la expresión corporal permite comprender las causas que estimulan y bloquean los procesos de aprendizaje, y así, nutrir el enfoque multidisciplinar que requiere la investigación de la expresión corporal y de la danza (SEVDALIS; KELLER, 2011). 


Lack of inhibition, spontaneity and codification
as perceived by the student of corporal
expression
Abstract: This article aims to identify student's
perceptions regarding the lack of inhibition, spontaneity
and codification of the tasks associated with corporal
expression. The study sample comprised 18 students
(24.46 \pm 2.22 years old) of corporal expression at the
University of Vigo (Spain). A content analysis of the
student's logbooks was undertaken. Data was
processed using the NVIVO 8 software. Results
showed that visual and tactile interaction inhibits
expressive commitment, instructions based on
metaphors facilitate spontaneous movement and
codification of gestures favours the transmission of
messages.
Keywords: Education. Perception. Dancing.

Desinibição, espontaneidade e codificação percebida pelos alunos de expressão corporal Resumo: Este artigo examina as percepções a respeito da desinibição, espontaneidade, e a codificação de alunos e alunas nas tarefas da disciplina de expressão corporal. A amostra foi composta por 18 pessoas $-24,46 \pm 2,22$ anos-, alunos/ as da Universidade de Vigo (Espanha). Análise dos dados foi realizada pela técnica de análise de conteúdo dos diários de práticas dos alunos/as. Para o tratamento dos dados foi utilizado o software de análise qualitativa NVIVO8. Os resultados mostraram que: a interação visual e tátil inibe o compromisso expressivo, os slogans com base em metáforas facilitam o movimento espontâneo e a codificação do gesto favorece a transmissão de mensagens.

Palavras-chave: Educação. Percepção. Dança.

\section{REFERENCIAS}

ARTEAGA, M.; VICIANA, V.; CONDE, J. Desarrollo de la expresividad corporal. Barcelona: Inde, 1999.

BILBENY, N. La revolución en la ética. Barcelona: Anagrama, 1997.

BOURDIEU, P. Notas provisionales para la percepción social del cuerpo. En: ÁLVAREZ-URÍA (ed.). Materiales de sociología crítica. Madrid: La piqueta, 1986. p. 37-56. 
CANALES, I. De la expresión a la comunicación: una propuesta didáctica. Sevilla: Wanceulen, 2010a.

CANALES, I. La desinhibición en la expresión corporal: una propuesta didáctica. Sevilla: Wanceulen, 2010b.

CANALES, I. La mirada y el tacto en la expresión corporal: consecuencias pedagógicas y propuesta de intervención. Saarbrücken: Académica Española, 2011.

COCA, S. Comunicación y creatividad: la expresividad creativa del gesto. 1988. 213 p. Tesis (doctoral) - Universidad Complutense de Madrid, Madrid, 1988.

DE SOUSA, N.C.P.; CARAMSCHI, S. Body contact between adolescents through ballroom dancing at school. Motriz. Revista de Educação Física, Rio Claro, v. 17, n. 4, p. 618-629. Oct. 2011.

FAJARDO, L. La metáfora como proceso cognitivo. Forma y función, Bogotá, n. 19, p. 47-56, 2006. Disponible en: http://redalyc.uaemex.mx/redalyc/pdf/219/ 21901903.pdf. Acceso en: 12 jul. 2012.

HANNA, J.L. A nonverbal language for imagining and learning: dance education in K-12 curriculum. Educational Researcher, Thousand Oaks, v. 37, n. 8, p. 491506, 2008.

HEINEMANN, K. Introducción a la metodología de la investigación empírica. Barcelona: Paidotribo, 2003.

LAGERLOF, I.; DIERF, M. Children's understanding of emotion in dance. European Journal of developmental psychology, East Sussex, v. 6, n. 4, p. 409-431, 2009.

LUSSIER-LEY, C.; DURAND-BUSH, N. Exploring the role of feel in the creative experiences of modern dancers: a realist tale. Research in Dance Education, Silver Spring, v. 10, n. 3, p. 199-217, 2009.

MARKS, L. E. The Unity of the Senses: Interrelations Among the Modalities. New York: Academic ,1978.

MEIRIEU, P. Frankestein educador. Barcelona: Laertes, 1998.

MERLEAU-PONTY, M. Fenomenología de la percepción. Barcelona: Península, 1980.

PRISBELL, M. Perception differerences and levels of shyness.Communication Research Reports, Pittsburgh, v. 5, n. 2, p. 197-203, 1988.

RIBEIRO, M.M.; FONSECA, A.The empathy and the structuring sharing modes of movement sequences in the improvisation of contemporary dance. Research in dance education, Silver Spring, v. 12, n. 2, p. 71-85, 2011. 
ROVIRA, G. La conciencia sensitiva en la formación docente. Estudio de casos: las vivencias de los estudiantes de magisterio suscitadas en la práctica de situaciones motrices introyectivas. 2010. 303 p. Tesis (doctoral) - Lleida. Universidad de Lleida, 2010. Disponible en: <http://www.tesisenred.net/handle/10803/8204>. Acceso en: 7 de jul. 2012.

SANTIAGO, P. De la expresión corporal a la comunicación interpersonal. Madrid: Narcea, 1985.

SAWADA, M.; MORI, S.; ISHII, M. Effect of metaphorical verbal instuction on modeling of sequential dance skills by young children. Percept Motor Skills, Missoula, v. 95 , n. 3, p. 1097-1105, 2002.

SIERRA, M.A. La expresión corporal desde la perspectiva del alumnado de educación física. 2002. 250 p. Tesis (doctoral) - Universidad Complutense de Madrid, Madrid, 2002.

SEVDALIS, V.; KELLER, P.E. Captured by motion: dance, action understanding, and social cognition. Brain and Cognition, San Diego, v. 77, n. 2, p. 231-236, nov. 2011.

STOKOE, P.; SIRKIN, A. EI proceso de la creación en arte. Buenos Aires: Almagesto, 1994.

TORRENTS, C. Los recursos expresivos en la expresión corporal universitaria. En: SÁNCHEZ Y COTERÓN (eds.). La expresión corporal en la enseñanza universitaria. Salamanca: Ediciones Universidad de Salamanca, 2012. p. 81-94.

TORRENTS, C. et al. Posibilidades de las tareas de expresión corporal para suscitar emociones en el alumnado. Revista de psicología del deporte, Barcelona, v. 20, n. 2, p. 401-412, 2011.

WESTLAND, G. Physical touch in psychotherapy: Why are we not touching more? Body, Movement and Dance in Psychotherapy: an International Journal for Theory, Research and Practice, Londres, v.6, n. 1, p. 17-29, 2011.

Endereço para correspondência:

Inma Canales-Lacruz

Facultad de Educación

Universidad de Zaragoza

c/ San Juan Bosco 7

50009 Zaragoza (España)

Recebido em: 14.08.2012

Aprovado em: 03.06.2013 